Bull. Chem. Soc. Ethiop. 2021, 35(1), 171-184.

(c) 2021 Chemical Society of Ethiopia and The Authors

ISSN 1011-3924

DOI: https://dx.doi.org/10.4314/bcse.v35i1.15

Printed in Ethiopia

Online ISSN 1726-801X

\title{
STUDIES ON PHYSICO-MECHANICAL BEHAVIOUR OF KENAF/GLASS FIBER REINFORCED EPOXY HYBRID COMPOSITES
}

\author{
Abdullahi Haruna Birniwa ${ }^{1,2^{*}}$, Shehu Sa'ad Abdullahi ${ }^{3,4}$, Maimuna Yahaya Yakasai ${ }^{5}$ and \\ Adamu Ismaila ${ }^{6}$ \\ ${ }^{1}$ Department of Chemistry, Sule Lamido University Kafin Hausa, Jigawa State, Nigeria \\ ${ }^{2}$ Department of Chemistry, Faculty of Science, University of Malaya, Kuala Lumpur, Malaysia \\ ${ }^{3}$ Department of Polymer Technology, Hussaini Adamu Federal Polytechnic Kazaure, Jigawa \\ State, Nigeria \\ ${ }^{4}$ School of Chemical Sciences, Universiti Sains Malaysia, USM Pulau Pinang, Malaysia \\ ${ }^{5}$ Department of Chemistry, Sa'adatu Rimi College of Education, Kano state Nigeria \\ ${ }^{6}$ Department of Chemistry, Bayero University Kano, Nigeria
}

(Received November 26, 2020; Revised April 17, 2021; Accepted April 27, 2021)

\begin{abstract}
In this study, various treated, untreated, and treated kenaf/glass fiber composites were fabricated using epoxy resin. A portion of kenaf fibers were subjected to treatment with alkali, sub-portion was taken for benzoyl peroxide and potassium permanganate prior to composite fabrication. This treatment on the composite material was undertaken to achieve improved modification of the interface between the matrix and fiber bond. A portion of the glass fiber was used for enhancing the mechanical properties of the hybrid composite. The tensile strength, flexural, density, water absorption and chemical resistance of the composites were analyzed using standard methods. FTIR was conducted on the fiber to ascertain the chemical treatment on the fibers, FESEM was used for the morphological study. The results obtained showed that the tensile and flexural strength improved from 46.45-298.3 kgf, and 10.5-54.7 kgf, respectively, in the composite samples. Chemical resistance of the kenaf fiber treated potassium permanganate composite improved compared to the untreated fiber composite in both cases. The density and water absorption properties of the composites were found to decrease in the treated fibers compared to untreated fiber composites, this treated composites showed less water absorption and density. The FTIR result revealed that reaction has taken place between the fiber and the treatment reagent. Hence, fiber modification has improved the properties of the composites due to increase in fiber-matrix interaction.
\end{abstract}

KEY WORDS: Chemical properties, Epoxy resin, Hybrid, Kenaf, Mechanical strength, Natural fiber

\section{INTRODUCTION}

As the commercial use of kenaf extends beyond its historical position as a cordage crop (rope, twine, and sackcloth) to new applications such as paper, construction materials, composite, absorbents, and livestock feed, the number of options available in the decision matrix will rise. Kenaf (Hibiscus cannabinus L., Malvaceae) is a warm-season annual fiber crop like cotton and okra that can be cultivated successfully in many parts of the world. Understanding the many different aspects of kenaf development as a fiber would be needed for these management decisions. As a result of favorable results in the economic and environmental friendliness of natural fiber properties relative to synthetic fibers, there has been a substantial rise in the number of applications of natural fibers in different industries [1]. Natural fibers are made from plants that contain lignocellulose substances and are environmentally sustainable because of their resilience, reusability, and biodegradability [2]. Researchers have extracted fibers from softwoods and hardwoods in order to use them in the development and study of polymer composites [3-4]. Natural fiber composites have many characteristics that make them bold to industries and commonly preferred to traditional composites, with recent studies demonstrating

*Corresponding author. E-mail: birniwa01@gmail.com

This work is licensed under the Creative Commons Attribution 4.0 International License 
the advantages of natural fiber composites and explaining their choice [5]. Natural fibers are non-synthetic, non-manmade fibers. They will come from either plants or animals [6]. Composite materials have been used since centuries ago and it all started with natural fibers, they have replaced so many conventional materials due to their eco-friendly nature, cheapness, and easy processing. Natural fibers have become important items in the economy and in fact they have turned out to be significant source of jobs for developing countries. Natural fibers in simple definition are fibers that are not synthetic or manmade. They can be sourced from plants or animals [7]. A composite material system is composed of two or more physically distinct phases whose combination produces aggregate properties that are different from those of its constituents, [8-9]. Composites are very important because of their strength and stiffness, yet very light in weight, compared to conventional materials [10]. The composites are compound materials which differ from alloys based on the fact that the individual components retain their characteristics, hence they tend to have improved properties such as tensile strength, flexural strength, impact strength, resistance to water and chemicals when used for various application [11-16]. Synthetic polymers are important because of the desirable properties of the resulting products. Epoxy resin, for example, is one of the polymer matrices that undergoes such modification due to its high strength, high stiffness, chemical stability, and low cost $[11,17]$.

Fiber reinforced polymer matrix got considerable attention in numerous applications because of the good properties and superior advantages of natural fiber over synthetic fibers in term of its relatively low weight, low cost, less damage to processing equipment, good relative mechanical properties such as tensile modulus and flexural modulus, improved surface finish of molded parts composite, renewable resources, being abundant. Polymers are usually divided into two types: thermosets and thermoplastics. Since the composition of thermoplastic matrix materials is made up of one or two dimensional molecular, these polymers appear to soften at higher temperatures and then roll back their properties as they cool [18]. Thermoset polymers, on the other hand, are strongly cross-linked polymers that cure using only heat, and strain, and/or light irradiation. Thermoset polymers have good properties because of this construction, such as high flexibility for tailoring desirable ultimate properties, great strength, and modulus [6]. The most widely used thermosetting matrices are phenolic, polyester, and epoxy resins [19, 20]. Fiber reinforced composites can be mass-produced in large numbers, are more environmentally friendly, and are thicker and lighter than other traditional materials like steel. At the micro and macroscopic scales, fiber reinforced polymer composites have varying physical and chemical properties [21].

Natural fibers are being investigated as a reinforcement for sheet moulding compounding materials for use in the building industry, according to researchers. Natural fibers can take the place of steel and concrete in building projects [22]. Natural fibers have several flaws, one of which is the variability of their properties. Establishing the impact resistance of natural fiberreinforced composites is one of the difficulties in testing their properties. Natural fiber reinforced composites' effect properties have been determined to be insufficient to deal with synthetic fiber reinforced composites [23]. As a result, hybridization (the use of more than one form of fiber in a matrix) has the ability to strengthen the weakest qualities of both natural and synthetic fibers while still being environmentally sustainable, with improved effect energy absorption and load carrying power, However, using only synthetic fibers in composites for structural applications is more costly, as previously mentioned. As a result, experts are looking at the feasibility of using mixed synthetic and natural fibers in structural composites to save costs [24]. For the present study, a composite material of bonded epoxy resin was made using natural fiber derived from kenaf and glass fibers. Changes in the physico-mechanical properties of the fiber filled with kenaf and glass fibers will also be studied. The natural fiber was subjected to chemical treatment to improve its surface chemistry. 


\section{EXPERIMENTAL}

\section{Chemicals and materials}

The epoxy resin bis(phenol-A-diglycidylether), crosslinker HY-951 and the glass fiber these chemicals were obtained from Nycil Nigeria Limited analytical grades, the resin was used as a matrix material with the grade LM-556 and density of $1.3 \pm 0.2 \mathrm{~g} / \mathrm{cm}^{3}$. Sodium hydroxide (NaOH) $99 \%$ purity, benzoyl peroxide $99 \%$ purity, hydrogen peroxide $99 \%$ purity, potassium permanganate $\mathrm{KMnO}_{4} 99 \%$ purity and non-ionic detergent were all purchased from Sigma Aldrich. The kenaf fiber was obtained from a local farm in Kazaure local government, Jigawa State Nigeria (Latitude: $12^{\circ} 38^{\prime} 54.46^{\prime \prime N}$ Longitude: $8^{\circ} 24^{\prime} 42.41^{\prime \prime}$ E.).

\section{Methods}

\section{Fiber extraction}

The Kenaf fiber was removed using water retting method. Therefore, the leaves of fiber which was removed from its tree were immersed in a trough of water at room temperature for seven days. The fiber is known to contain pectin, lignin, and other impurities and gummy materials in it developed an awful odour. Within a sheath of networked framework, the fiber looked new and milky. By hand scraping the residual fiber was collected and carded with a smooth nylon brush. This was washed multiple times with tap water before it was cleaned and permitted to dry under the shade for three days [10]. A hand nylon brush was used to clean the dry thread, resulting in a fine strand of the substance ready for application and composite fabrication.

\section{Alkaline treatment of kenaffiber}

The fiber was washed initially with non-ionic detergent many times, 2 percent detergent remedy non-ionic detergents are gentler than ionic detergents and they have a restricted capacity to disrupt protein-protein interactions in the kenaf fiber. After that, it was immersed in a 5\% sodium hydroxide solution $(\mathrm{NaOH})$ in thermostat machine for three hours at $96{ }^{\circ} \mathrm{C}$. It was for the hydroxyl (OH-) activation cellulose group within the fiber and to attach the sodium ion $\left(\mathrm{Na}^{+}\right)$to the fiber backbone in order to make it more hydrophobic [22]. Excess delignification of natural fibers may occur at higher concentrations above 5 per cent, resulting in weakened or degraded fiber. Then, the fiber was extensively cleaned with distilled water and later insert in the oven to dry for 24 hours in an air-flow at $70{ }^{\circ} \mathrm{C}$. The fiber was called alkali-treated kenaf fiber [8].

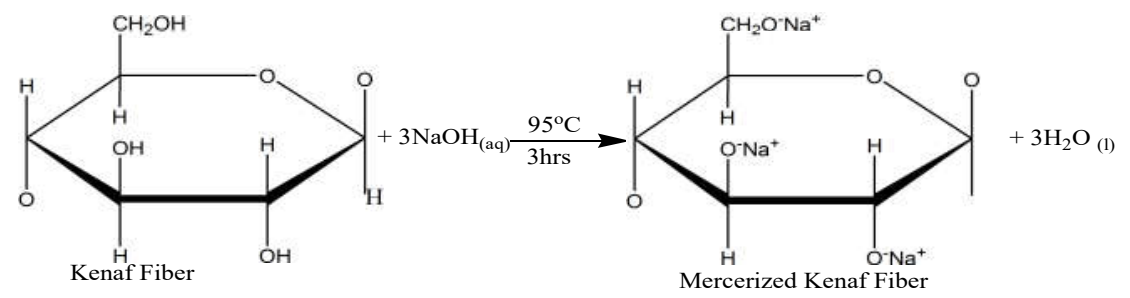

Scheme 1. Alkaline treatment of kenaf fiber.

\section{Peroxidation}

The fiber was washed with $2 \%$ non-ionic detergent solutions and soaked in $2 \% \mathrm{NaOH}$ solution for 1 hour. It was subsequently immersed in benzoyl peroxide ( $6 \%$ concentration) solution in 
acetone for $30 \mathrm{~min}$. Some portions of the material were immersed in hydrogen peroxide instead of benzoyl peroxide for the purpose of comparisons. Complete decomposition of peroxide was achieved by heating the solution at higher temperature $180^{\circ} \mathrm{C}$. The kenaf fiber was designated as benzoyl treated $[7,25]$.

\section{Potassium permanganate $\mathrm{KM}_{n} \mathrm{O}_{4}$ treatment}

A $0.125 \%$ of potassium permanganate $\mathrm{KMnO}_{4}$ was dissolved into $90 \mathrm{~mL}$ of water and $6 \%$ of acetone was added to the solution. $15 \mathrm{~g}$ of alkali treated kenaf fiber was dipped inside the solution and kept for 30 minutes. After $30 \mathrm{~min}$, the fiber was sieved and dried under shade for 7 days at room temperature $[7,25]$. The significance of all these treatments is to remove impurities, waxes and pectin from the fiber and also makes it more hydrophobic.

\section{Polymer matrix}

The epoxy resin belongs to a class of thermosetting polymers that undergo cross linking when polymerized in the presence of a hardener (cross linker). The matrix material was prepared with a mixture of the epoxy resin and hardener in the volume ratio of 2:1 [26].

\section{Composite fabrication}

This composite was made using the hand lay-up method. To eliminating air bubbles, the epoxy resin and cross linker (60:40) were carefully combined with gentle stirring. A mold release agent was added to the inner surface of the mold for fast and simple removal of the composite sheets. A thin coating of the matrix mixture was sprayed over the mold, which was held on a glass tray. After that, the necessary amount of fiber was spread within the mixture. As seen in Figure 1, the remaining mixture was then poured into the mold. To stop the creation of air bubbles, a sonication machine was used. After allowing the mold to cure at room temperature for two hours, the samples were removed from the mold and held for further testing [10, 27].

\section{Fabrication of composite specimen}

A $140 \times 35 \times 10 \times 5 \mathrm{~mm}$ size mould was typically used to cast the composite sheet. The standard method of hand lying [7] was used to fabricate the composite samples as shown in Figure 1

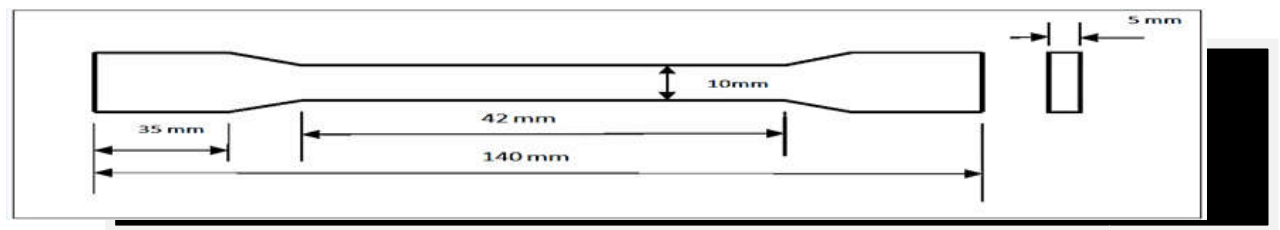

Figure 1. Schematic representation of the mold used.

\section{Moisture absorption test}

Water absorption is used to determine the amount of water absorbed under specified condition. The test specimen was manufactured as per ASTM standard D570-98 [28]. The water absorption is expressed as increasing weight percent. The high moisture absorption capacity of natural fibers adversely affects adhesion with a hydrophobic matrix and, as a result, it may cause material degradation and loss of strength [10]. The composite was pre-weight $\left(\mathrm{W}_{1}\right)$ and 
immersed in their respective cylinder containing distilled water for 24 hours. After the sample was dried by pressing both side of the composite with tissue paper and re-weight $\left(\mathrm{W}_{2}\right)$. The \% weight loss/weight gained of the composite was evaluated as reported by [29] using equation 1 .

$\%$ weight $=\frac{W 2-W 1}{W 1} X 100 \%$

where $\mathrm{W}_{1}=$ initial weight, $\mathrm{W}_{2}=$ final weigh of the sample.

\section{Chemical resistance test}

The composite was put into a chemical test with acid $\left(\mathrm{H}_{2} \mathrm{SO}_{4}\right.$ and $\left.\mathrm{HCl}\right)$ and base $\left(\mathrm{NH}_{4} \mathrm{OH}\right.$ and $\mathrm{KOH}$ ). According to ASTDM standard D-570 [25], the acid and base solution used were $10 \%$ in $90 \mathrm{~mL}$ of water. Each chemical was measured on the composite sample, the average value was calculated, and the composite was pre-weighted recorded as $\left(\mathrm{W}_{1}\right)$ and dipped into the respective cylinders at room temperature for 24 hours. Once the sample has been cleaned with purified water and dried by absorbing the surface moisture with tissue paper of the sample, it can be reweighted as soon as possible recorded as $\left(\mathrm{W}_{2}\right)$. The weight gain/loss of the samples was determined using equation 1 in the same way.

\section{Density}

The densities of the samples were calculated by using the equation 2 . Three of each different type of composites was tested, and the average value was reported.

Density $\left(\frac{g}{\mathrm{~cm}^{3}}\right)=\frac{m}{v}$

where $m$ is the mass of the composites $(g)$ and $v$ is the volume of the composites $\left(\mathrm{cm}^{3}\right)$.

Tensile strength test

Following ASTM D3039 / D3039M-00 (2006) method, [30]. Traction strength of dog bone shape specimens of 140 to 35 to $10 \mathrm{~mm}$ was performed using the standard ultimate testing machine (UTM), Shimadzu (Model AG-1) with $20 \mathrm{~mm} / \mathrm{min}$ cross head speed [17, 26].

\section{Flexural test}

An Instron IX 4302 unit, using the 3-point bending feature according to ASTMD-790, was also used for flexural checks. A cross-head speed was used at $5 \mathrm{~mm}$ per minute. The test sample dimensions were typically 60x 6x $2 \mathrm{~mm}$. The composite findings were collected from 3 research specimens. The value of the flexural force $(\pi)$ was calculated in accordance with equation 2 $=3 \mathrm{FL} /\left(2 \mathrm{dh}^{\wedge} 3\right)[25]$.

\section{Fourier transform infrared (FTIR)}

The treated and untreated fibers were analyzed with Agilant Cary 630 FT-IR spectrometer at room temperature FT-IR spectra were recorded on the fiber samples. The spectra of the fibers were obtained within the frequency range of $4000-600 \mathrm{~cm}^{-1}$.

Field emission scanning electron microscopy (FESEM)

The surface morphology was observed via field emission scanning electron microscopy (FESEM) [Hitachi Brand, Model SU 8220] with different magnifications. 


\section{RESULTS AND DISCUSSION}

The aims of the chemical treatment was to enhance changes on the surface of the kenaf fiber, this revealed more reactive groups on the surface and eased the smoothness for coupling between the kenaf fiber and the epoxy resin, as such the mechanical properties of the kenaf fiber would have improved. The mechanical properties of the composite rely on the type of fiber and matrix used. This further depends on the quality of the fiber, the increase in fiber content leads to improved tensile and flexural properties. It was observed that the tensile and flexural properties of kenaf fiber reinforced composites improved with alkali, benzoylation and potassium permanganate treatment. The result of tensile presented in Figure 2 indicates that, the tensile strength of potassium permanganate treated kenaf fiber reinforced epoxy resin composite (PKEC) is much higher compared to the remaining composites samples, (PKEC) having the highest tensile strength of $298.3 \mathrm{kgf} / \mathrm{mm}$ while untreated kenaf epoxy composite had the least tensile strength of $46.45 \mathrm{kgf} / \mathrm{mm}$. The alkali treatment of the kenaf natural fiber gave rise to the development of cellulose- $\mathrm{O}-\mathrm{Na}^{+}$groups on the surface material. The Hydrogen bonding existing between the backbone structures is broken while new reactive hydrogen bonds are formed between the cellular, molecular chains, and the natural crystalline structure of the cellulose relaxed. Hence, the addition of aqueous sodium hydroxide to the kenaf natural fiber stimulated the ionization of the hydroxyl group to the alkoxide (Scheme 1). Washing of the fiber later permitted a reaction of Oxygen with water to create more hydroxyl groups on the surface of the kenaf fiber. This created hydrogen bond and allowed a neutral $\mathrm{pH}$ to be attained $[10,26$, $31,32]$.

As a result of the alkali treatment (Scheme 1), activation of hydroxyl groups and at the same time cleaning of the surface of cellulosic fiber was created. Removing any proportion of pectin adhesive, hemicellulose, lignin, waxy epidermal material, and oil covering resulted in decreased fiber diameter and an improvement in aspect ratio. This also raises the surface area of the working fiber for excellent matrix adhesion [13]. As stated in [33], the treatments resulted in increased roughening of the base, thereby facilitating mechanical bonding. From the analysis in Figures 2 shows the alkali, benzoylation and potassium permanganate treatment with kenaf fiber/glass fiber/epoxy composites displayed better mechanical tensile and flexural properties values when contrasting those with untreated kenaf epoxy Composites. Peroxidation reaction using benzoyl peroxide tends to crumble easily to form free radicals of the $\mathrm{RO}$ - form; $\mathrm{RO}$ • forming cellulose radical with subsequent reactions occurring with the hydrogen group of cellulose fibers. The Free-Radical Reaction initiated by peroxide and potassium permanganate follows similar trend $[8,32,33]$. As shown in Scheme 2 and 3, respectively:

$$
\begin{gathered}
\mathrm{RO}-\mathrm{RO} \rightarrow 2 \mathrm{RO} \bullet \\
\mathrm{RO} \bullet+\text { Cellulose }-\mathrm{H} \rightarrow \mathrm{ROH}+\text { Cellulose }
\end{gathered}
$$

Scheme 2. Reaction of kenaf fiber with benzoyl peroxide.

This treatment reduces the tendency of the fiber to absorb moisture and improves dimensional stability, it has been reported that potassium permanganate treatment has led to higher mechanical properties of composites. As shown in Figures 2 and 3 (left), when compared with the remaining composites samples, potassium permanganate treated kenaf epoxy composite showed increased mechanical properties tensile and flexural values. 
Potassium permanganate treatment on kenaf fiber

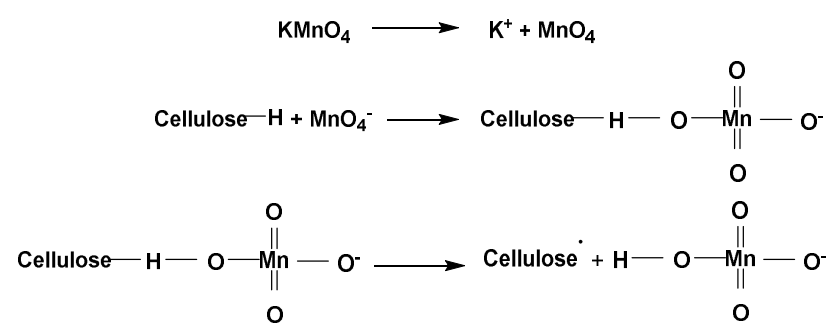

Scheme 3. Reaction of kenaf fiber with potassium permanganate.

\section{Moisture absorption}

The hygroscopic natural fiber-reinforced composite is obvious in nature; hence the water significantly affects the composites. The natural fibers are water and bulge absorbents. This affects the fiber-resin interface, thereby destroying the mechanical properties. Water reaches the natural fiber and splits fibrils from the natural fiber. The properties of the fiber losses considerably. Nevertheless, its tolerance to water after improved modification of the fiber by composite shape, as seen in Table 1. This result agrees with the finding of [25].

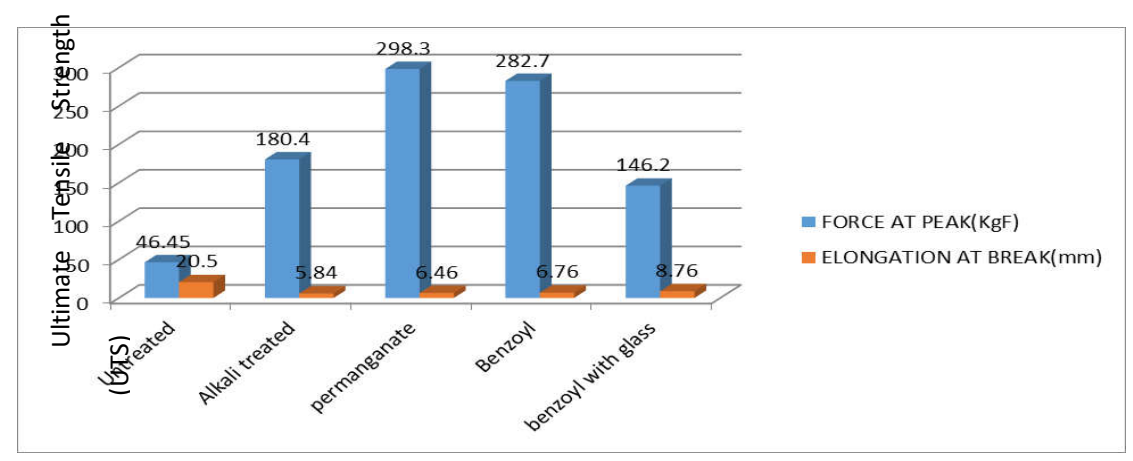

Figure 2. Tensile strength of the treated and untreated samples.

Table 1. Moisture absorption test.

\begin{tabular}{|l|l|l|c|}
\hline Samples & Initial weight $(\mathrm{g})$ & Final weight $(\mathrm{g})$ & \% Change weight \\
\hline Untreated kenaf & 12.30 & 12.60 & +2.440 \\
\hline Alkali treated kenaf & 12.30 & 12.31 & +0.081 \\
\hline Treated $\mathrm{KMnO}_{4}$ kenaf & 12.21 & 12.21 & 0 \\
\hline Benzoyl peroxide treated kenaf & 12.30 & 12.30 & 0 \\
\hline $\begin{array}{l}\text { Benzoyl peroxide treated } \\
\text { kenaf/glass }\end{array}$ & 12.20 & 12.20 & 0 \\
\hline
\end{tabular}


Table 2. Density test.

\begin{tabular}{|l|c|}
\hline Composite samples & Density $\left(\mathrm{gcm}^{3}\right)$ \\
\hline Untreated kenaf & 0.100 \\
\hline Alkali treated kenaf & 0.088 \\
\hline $\mathrm{KMnO}_{4}$ treated kenaf fiber & 0.076 \\
\hline Benzoyl peroxide treated kenaf fiber & 0.083 \\
\hline Benzoyl peroxide/glass fiber (hybrid) & 0.092 \\
\hline
\end{tabular}

\section{Density test}

The density of the untreated was found to be $0.100 \mathrm{~g} / \mathrm{cm}^{-1}$, whereas the treated fibers show a value of $0.076 \mathrm{~g} / \mathrm{cm}^{-1}$ as shown in Table 2 . Removal of the surface impurities probably helped to decrease the density of the fiber as well as the composites. The decreased density indicates the compactness of the blends as well as improved interfacial adhesion between fiber and matrix for the case of treated fiber composite with coupling agent.
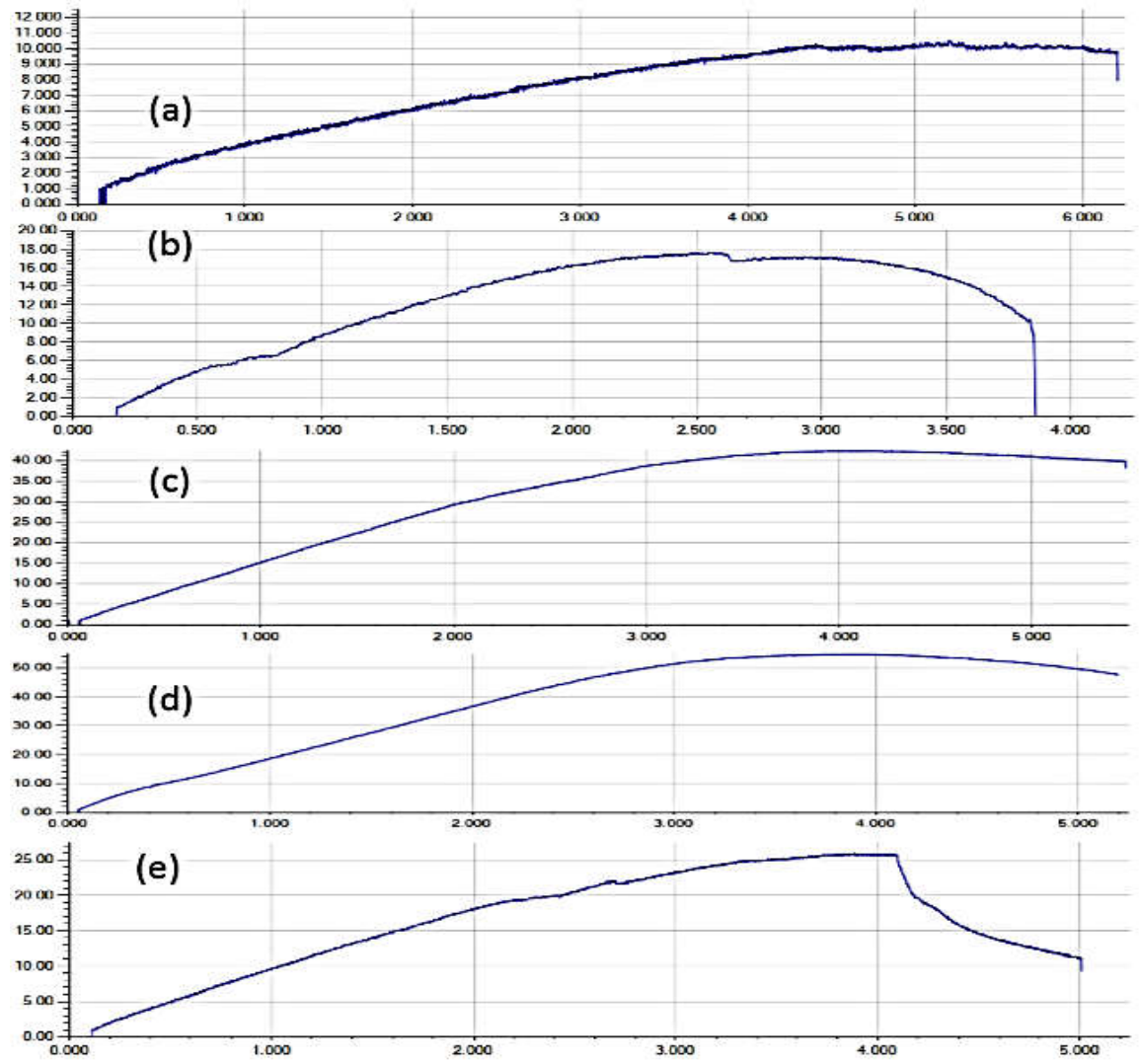

Figure 3. Graph of flexural strength samples (a) untreated kenaf fiber, (b) benzoyl peroxide treated, (c) alkali treated, (d) permanganate treated and (e) benzoyl peroxide/glass fiber, respectively. 


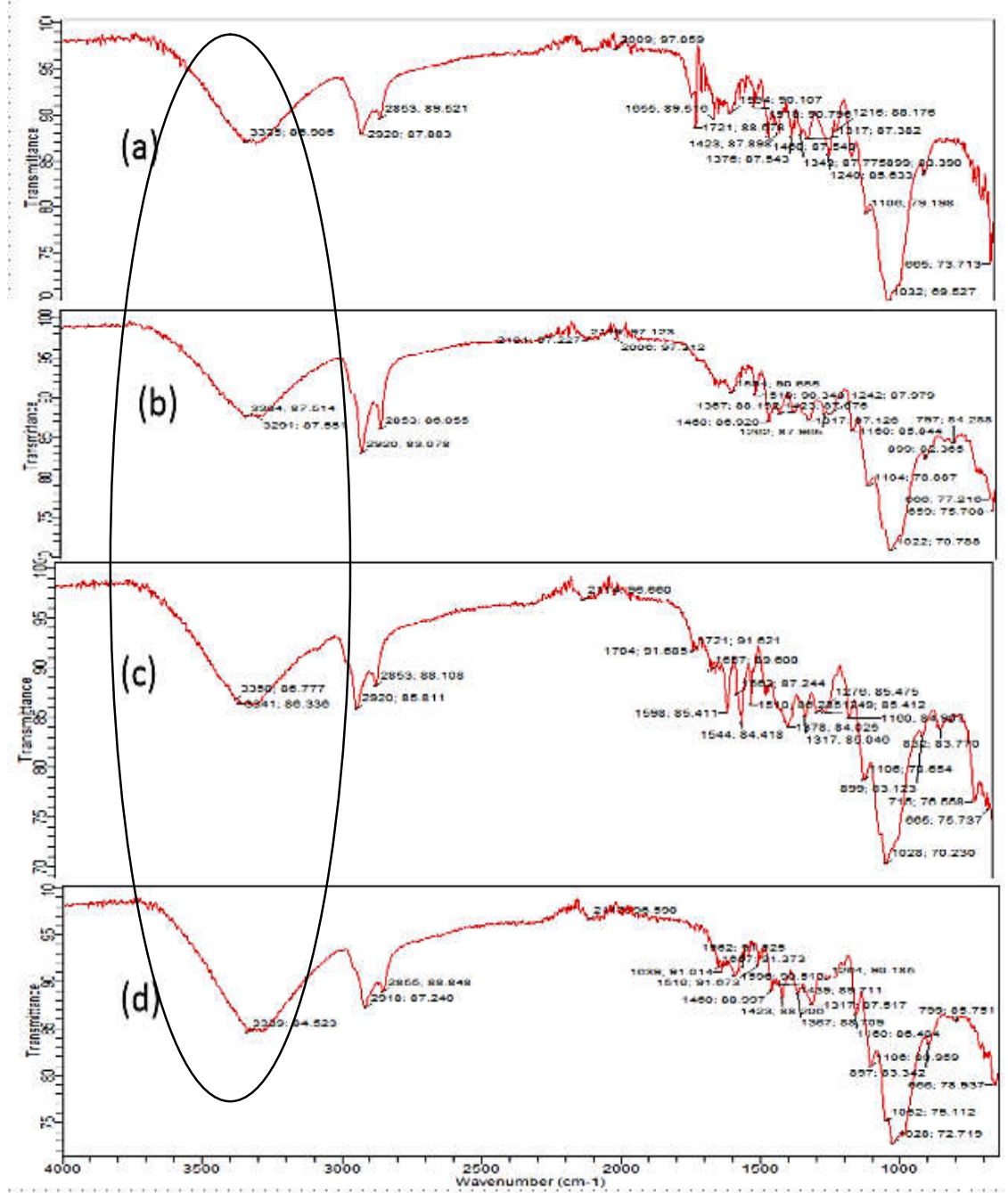

Figure 4. Graph FITR for samples (a) untreated kenaf fiber, (b) benzoyl peroxide treated, (c) alkali treated and (d) permanganate treated, respectively.

\section{Chemical resistance}

The chemical treatment, namely, alkali, potassium permanganate, benzoylation were conducted to improve the hydrophobic nature of the kenaf fiber. When the kenaf fibers are subjected to chemical treatment, hemicellulose, lignin pectin, moisture and other impurities are removed. The alkaline treatment of fibers helps in improving the chemical bonding between the resin and the fiber resulting in superior mechanical properties. Chemical treatment of kenaf fiber cause fibrillation of fibers to small fibrils, with the decrease in fiber diameter, surface area increases which leads to wet ability of fibers within the matrix. The interfacial area is the most favourable aspect of composite for this purpose, acids and base were used as shown in Table 3-6. 
Table 3. Reaction with $10 \%$ potassium hydroxide.

\begin{tabular}{|l|l|l|l|}
\hline Composite samples & Initial weight $(\mathrm{g})$ & Final weight $(\mathrm{g})$ & \% Change weight gain/lost \\
\hline Untreated kenaf fiber & 12.20 & 12.41 & +1.721 \\
\hline Alkali Treated kenaf fiber & 12.20 & 12.22 & +0.164 \\
\hline $\mathrm{KMnO}_{4}$ treated kenaf fiber & 12.50 & 12.50 & 0 \\
\hline Benzoyl peroxide treated fiber & 12.47 & 12.47 & 0 \\
\hline $\begin{array}{l}\text { Benzoyl peroxide treated/glass } \\
\text { fiber }\end{array}$ & 12.30 & 12.30 & 0 \\
\hline
\end{tabular}

Table 4. Reaction with $10 \% \mathrm{NH}_{4} \mathrm{OH}$.

\begin{tabular}{|l|l|l|l|}
\hline Composite samples & Initial weight $\mathrm{W}_{1}$ & Final weight $\mathrm{W}_{2}$ & \% weight gain/lost \\
\hline Untreated kenaf fiber & 12.30 & 12.70 & +3.252 \\
\hline Alkali treated kenaf fiber & 12.20 & 12.21 & +0.082 \\
\hline $\begin{array}{l}\mathrm{KMnO}_{4} \text { treated kenaf } \\
\text { fiber }\end{array}$ & 12.30 & 12.30 & 0 \\
\hline $\begin{array}{l}\text { Benzoyl peroxide treated } \\
\text { kenaf fiber }\end{array}$ & 12.50 & 12.50 & 0 \\
\hline $\begin{array}{l}\text { Benzoyl peroxide/glass } \\
\text { fiber (hybrid) }\end{array}$ & 12.40 & 12.40 & 0 \\
\hline
\end{tabular}

Table 5. Reaction with $10 \%$ sulfuric acid.

\begin{tabular}{|l|l|l|l|}
\hline Composite samples & Initial weight $\mathrm{W}_{1}$ & Final weight $\mathrm{W}_{2}$ & \% weight gain/lost \\
\hline Untreated kenaf fiber & 12.2 & 12.5 & +2.46 \\
\hline $\begin{array}{l}\text { Alkali treated kenaf } \\
\text { Fiber }\end{array}$ & 12.60 & 12.50 & -0.79 \\
\hline $\begin{array}{l}\mathrm{KMnO} \text { treated } \\
\text { kenaf fiber }\end{array}$ & 12.30 & 12.30 & 0 \\
\hline $\begin{array}{l}\text { Benzoyl peroxide treated } \\
\text { kenaf fiber }\end{array}$ & 12.90 & 12.90 & 0 \\
\hline $\begin{array}{l}\text { Benzoyl peroxide/glass fiber } \\
\text { (hybrid) }\end{array}$ & 12.70 & 12.70 & 0 \\
\hline
\end{tabular}

Table 6. Reaction with $10 \% \mathrm{HCl}$.

\begin{tabular}{|l|l|l|l|}
\hline Composite samples & Initial weight $(\mathrm{g})$ & Final weight $(\mathrm{g})$ & \% Change in weight \\
\hline Untreated kenaf & 12.70 & 12.95 & +1.969 \\
\hline Alkali treated kenaf & 12.52 & 12.51 & -0.080 \\
\hline $\mathrm{KMnO}_{4}$ treated fiber & 12.61 & 12.61 & 0 \\
\hline $\begin{array}{l}\text { Benzoyl peroxide } \\
\text { treated kenaf peroxide }\end{array}$ & 12.34 & 12.34 & 0 \\
\hline $\begin{array}{l}\text { Benzoyl fiber } \\
\text { treated/glass } \\
\text { hybrid) }\end{array}$ & 12.40 & 12.40 & 0 \\
\hline
\end{tabular}

The chemical resistance test shows that some of the composite are resistance to the chemical attack, i.e. they show an increases in weight in acids and alkaline, some of the composite are found to dissolve in the acid and base. This is observed due to decrease in weight in some composite. The result shows that all treated composites/hybrid are more resistant to chemical attack compared to untreated composites which mostly absorbed chemical when coming in contact with this was due to absent of active interfacial cohesion between the fiber and resin because the untreated fiber is highly hydrophilic whereas the epoxy resin is hydrophobic in 
nature, but in the case of composites made from treated fiber some degree of hydrophobicity is imparted on them which result in good compatibility between the fibers and resin [25].

\section{Flexural properties}

The results are shown in Figure 3. The figure showed the flexural strength samples (a) untreated kenaf fiber, (b) benzoyl peroxide treated, (c) alkali treated, (d) permanganate treated and (e) benzoyl peroxide/glass fiber, respectively. The treated permanganate composite has the highest flexural strength, followed by alkali treated kenaf fiber, hybrid benzoyl/glass fiber, and benzoyl peroxide sample, which has the lowest flexural strength as compared to untreated composite; this is because both treated fiber and epoxy resin are naturally hydrophobic; therefore there is strong consistency with them. Untreated kenaf fiber is rich in impurities (hydrophilic), while epoxy resin is hydrophobic. Thus there is no good compatibility between them [14].

\section{FTIR analysis}

Figure 4 (a), (b), (c) and (d) shows the FT-IR spectra of untreated, benzoyl peroxide, alkali, $\mathrm{KMnO}_{4}$ the result showed the FTIR spectral peaks for both treated and untreated kenaf fibers. All the studied fibers have O-H stretching vibrations in the range of $3630-3326 \mathrm{~cm}^{-1}$. C-H stretch was located in the range of $2935-2916 \mathrm{~cm}^{-1}$ obtained from methylene, $\mathrm{C}=\mathrm{C}$ was found in the range of $1655-1639 \mathrm{~cm}^{-1}$ obtained from lignin, C-O stretching vibrations from ether were observed in the range of $1032-1007 \mathrm{~cm}^{-1}$ and $\mathrm{C}=\mathrm{C}$, bending for alkene in the range of 791-661 $\mathrm{cm}^{-1}$ were observed. It has been observed that all fibers exhibited similar peaks, but the intensity of the peaks increases upon treatment as seen in Figure 4. Treated kenaf fibers changes in the intensities of the treated were observed. The peaks in range from $3200 \mathrm{~cm}^{-1}$ to $3650 \mathrm{~cm}^{-1}$ are attributable to the $-\mathrm{OH}$ functional group. The intensities within this region were reduced for the case of treated fibers. This may be due to the enzymatic action by reducing the hydrogen bonding in cellulosic hydroxyl groups, thereby decreasing - $\mathrm{OH}$ concentration. This intensity decrease was also attributed to hemicelluloses removal, and as a result, the $\mathrm{OH}$ groups of the cellulose are exposed. The better degree of exposure may permit the reinforcing fiber to mechanically entangle with the polymer matrix more strongly. All the FT-IR spectra of untreated, alkali, $\mathrm{KMnO} 4$, benzoyl peroxide treated fibers are similar, but the intensity of the peaks increases due to the treatment on the fiber by removing impurities, such as lignin, hemicellulose, pectin and waxes $[10,25]$. The treatment makes the fiber more hydrophobic and more compactable with the epoxy resin during formation of the composites which results in an improved mechanical strength of the composites [10].

\section{Morphology studies}

Field emission scanning electron microscopy (FESEM) study was carried out to study the fractured surfaces of tensile, tested specimens. Fiber pull out, and voids are observed due to fiber pull-out and fiber the bonding. It is because of poor adhesion between the untreated kenaf and epoxy matrix. It is also observed that the fiber failure mode gives an indication of good load transfer through fibers and matrix as shown in Figure 5 (a) shows a clear untreated kenaf fiber, (b) treated kenaf fiber with $6 \%$ of $\mathrm{NaOH}$ without any reinforcement, (c) indicated the FESEM image of untreated kenaf fiber reinforced with epoxy resin while (d) shows treated kenaf fiber reinforced with epoxy resin. 

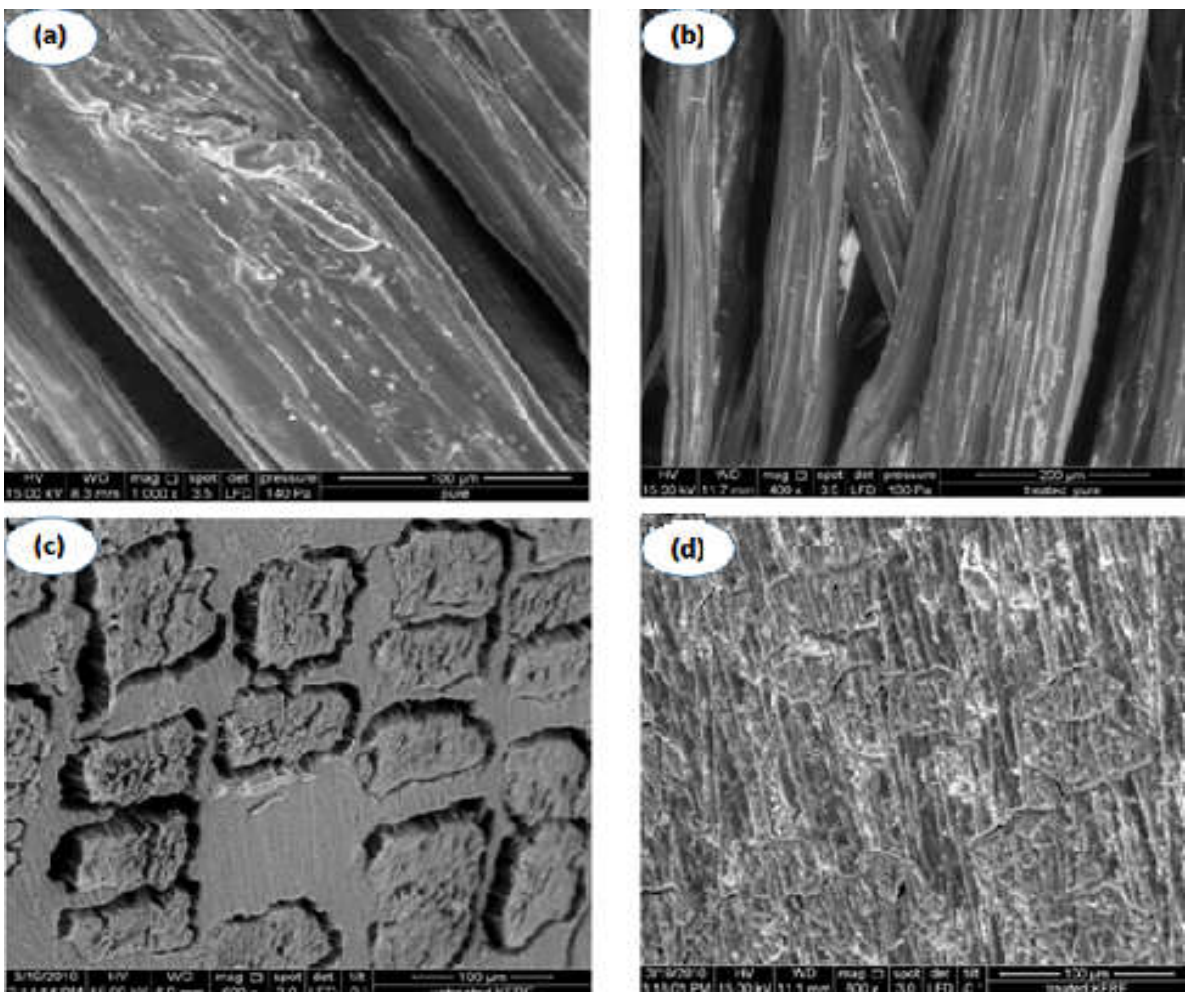

Figure 5. (a) Kenaf fiber before treatment, (b) kenaf fiber after treatment with alkali, (c) untreated kenaf epoxy composite and (d) treated kenaf epoxy composite.

\section{CONCLUSION}

This research demonstrates the efficient production of epoxy composites strengthened by kenaf fiber and kenaf/glass achieved by utilizing a direct hand lay-up technique. The surface modification is critical for decreasing the hydrophilicity of kenaf fibers and for improving the contact force with the hydrophobic structure of the matrix. The surface treatments of alkalization, benzoylation, and potassium permanganate used in this work modifying the cellulose component of the fiber influenced the mechanical properties of the resulting composites. These were tested effectively using FTIR as shown in the research. The test indicates that tensile strength can be determined for the handled fiber, the results showed that the treated blend kenaf potassium permanganate composites had a highest tensile and flexural strength compared to the remaining composite samples. This showed promising property in improving fiber resin interaction and mechanical test implies strong resistance and deformations encountered during usage of the composite for various applications.

\section{ACKNOWLEDGEMENTS}

Authors wish to acknowledge the Department of Chemistry, Faculty of Science, University of Malaya, for some characterizations and analysis, and would like to thank TET Fund IBR 20132014 (Nigeria) for the sponsorship. 


\section{REFERENCES}

1. Nasir, M.; Hashim, R.; Sulaiman, O.; Gupta, A.; Khan, T.A.; Jawaid, M.; Asim, M. Natural fiber improvement by laccase; optimization, characterization and application in medium density fiber board. J. Nat. Fibers 2017, 14, 379-389.

2. Saw, S.K.; Akhtar, K.; Yadav, N.; Singh, A.K. Hybrid composites made from jute/coir fibers: Water absorption, thickness swelling, density, morphology, and mechanical properties. J. Nat. Fibers, 2014, 11, 39-53.

3. Gupta, M.K.; Srivastava, R.K.; Kumar, S.; Gupta, S.; Nahak, B. Mechanical and water absorption properties of hybrid sisal/glass fibre reinforced epoxy composite. $J$. Polym. Sci. Eng. 2015, 3, 208-219.

4. Gupta, M.K.; Srivastava, R.K. Mechanical, thermal and water absorption properties of hybrid sisal/jute fiber reinforced polymer composite. Indian J. Eng. Mater. Sci. 2016, 23, 231-238.

5. Wang, G.; Chen, F. Development of bamboo fiber-based composites. Adv. High, Strength Nat. Fibre Compos. Constr. 2017, 235-255.

6. Ticoalu, A.; Aravinthan, T.; Cardona, F. A review of current development in natural fiber composites for structural and infrastructure applications. SREC 2010, 113-117.

7. Abdullahi, S.S.; Birniwa, A.H.; Mohammad, R.E.A.; Mamman, S.; Chadi, A.S. Impact of fibre reinforced polyester composites on tensile strength of baobab (Adansonia digitata) stem. Caliphate J. Sci. Technol. 2020, 2, 94-100.

8. Lala D.S.; Deoghare, A.B.; Chatterjee, S. Effect of dual pre-treatment on mechanical, morphological, electrical and thermal properties of rubber seed shellreinforced epoxy composites. Arab. J. Sci. Eng. 2019, 44, 845-856.

9. Ashik, K.P.; Sharma, R.S. A review on mechanical properties of natural fiber reinforced hybrid polymer composites. J. Miner. Mater. Charact. Eng. 2015, 3, 420426.

10. Birniwa, A.H.; Abdullahi, S.S.; Mahmud, H.N.M.E. Study on physico-mechanical behaviour of acacia nilotica (gum tree) and glass fiber blend reinforced epoxy resin composite. 2019, 10, 46-53.

11. Dadrasi, A.; Fooladpanjeh, S.; Gharahbagh, A.A. Interactions between HA/GO/epoxy resin nanocomposites: optimization, modeling and mechanical performance using central composite design and genetic algorithm. J. Braz. Soc. Mech. Sci. Eng. 2019, 41, 1-17.

12. Patel, D.P.K.S.H.; Parkhe, A. Mechanical behaviors of banana and sisal hybrid. Int. J. Res. - Granthaalayah 2016, 4, 206-216.

13. Xie, Y.; Hill, C.A.S.; Xiao, Z.; Militz, H.; Mai, C. Silane coupling agents used for natural fiber/polymer composites: A review. Compos. Part A Appl. Sci. Manuf. 2010, 41, 806-819.

14. Cai, J.; Fei, P.; Xiong, Z.; Shi, Y.; Yan, K.; Xiong, H. Surface acetylation of bamboo cellulose: Preparation and rheological properties. Carbohydr. Polym. 2013, 92, 11-18.

15. Popoola A.P.I.; Ezema, I.C. Gel time prediction of polyester resin for lamination of polymer composites. Bull. Chem. Soc. Ethiop. 2020, 34, 163-174.

16. Shang, L.; Zhang, M.; Liu, L.; Xiao, L.; Li, M.; Ao, Y.; Improving the interfacial property of carbon fibre/epoxy resin composites by grafting amine-capped cross-linked poly-itaconic acid. Surf. Interface Anal. 2019, 51, 199-209.

17. Wang, G.; Ma, L.; Yang, X.; Li, X.; Han, P.; Yang, C.; Cong, L.; Song, W.; Song, G. Improving the interfacial and flexural properties of carbon fiber-epoxy composites via the grafting of a hyperbranched aromatic polyamide onto a carbon fiber surface on the basis of solution polymerization. J. Appl. Polym. Sci. 2019, 136, 1-11.

18. Mohammed, L.; Ansari, M.N.M.; Pua, G.; Jawaid, M.; Islam, M.S. A review on natural fiber reinforced polymer composite and its applications. Int. J. Polym. Sci. 2015, 1-15. 
19. Ku, H.; Wang, H.; Pattarachaiyakoop, N.; Trada, M. A review on the tensile properties of natural fiber reinforced polymer composites. Compos. Part B Eng., 2011, 42, 856-873.

20. Yaqoob, A.A.; Umar, K.; Ibrahim, M.N.M. Silver nanoparticles: various methods of synthesis, size affecting factors and their potential applications-a review. Appl. Nanosci. 2020, 10, 1369-1378.

21. Yaqoob, A.A.; Ahmad, H.; Parveen, T.; Ahmad, A.; Oves, M.; Ismail, I.M.I.; Qari, H.A.; Umar K.; Ibrahim, M.N.M. Recent advances in metal decorated nanomaterials and their various biological applications: A review. Front. Chem. 2020, 8, 1-23.

22. Yaqoob, A.A.; Parveen, T.; Umar, K.; Ibrahim, M.N.M. Role of nanomaterials in the treatment of, waste water, a review. Water 2020, 12, 1-30.

23. Faruk, O.; Bledzki, A.K.; Fink, H.P.; Sain, M. Biocomposites reinforced with natural fibers: 2000-2010. Prog. Polym. Sci. 2012, 37, 1552-1596.

24. Safri, S.N.A.; Sultan, M.T.H.; Jawaid, M.; Jayakrishna, K. Impact behaviour of hybrid composites for structural applications: A review. Compos. Part B Eng. 2018, 133, 112-121.

25. Abdullahi, S.S.; Birniwa, A.H.; Chadi, A.S.; Mohammad, R.E.A.; Mamman. S. Effect of fiber surface modification on the mechanical properties of rice husk/glass fiber reinforcement epoxy resin hybrid composite. Niger. Res. J. Chem. Sci. 2020, 8, 147-162.

26. Montenegro, D.M.; Pappas, G.; Botsis, J.; Zogg, M.; Wegener, K. A comparative study of mode I delamination behavior of unidirectional glass fiber-reinforced polymers with epoxy and polyurethane matrices using two methods. Eng. Fract. Mech. 2019, 206, 485500 .

27. Dungani ,R.; Aditiawati, P.; Md, P.; Islam, P.; Jaman, N.A.; Hartati, S.; Sulaeman, A.; Sumardi, I.; Karliati, T.; Yuniarti, K.; Sutrisno Y. Evaluation of the Effects of Decay and Weathering in Cellulose-Reinforced Fiber Composites, Woodhead Publishing Series in Composites Science and Engineering: Online |publication; 2019; pp 173-210.

28. Rosado, M.J.; Puyana, V.P., Cid, P.S.; Guerrero, A.; Romero, A. Incorporation of ZnO nanoparticles into soy protein-based bioplastics to improve their functional properties, Polymers (Basel) 2021, 13, 486.

29. Venkateshwaran, N.; Elaya Perumal, A.; Alavudeen, A.; Thiruchitrambalam, M.; Mechanical and water absorption behaviour of banana/sisal reinforced hybrid composites, Mater. Des. 2011, 32, 4017-4021.

30. Altanopoulos T.I.; Raftoyiannis, I.G. Deriving tensile properties of glass fiber reinforced polymers (gfrp) using mechanics of composite materials Open J. Compos. Mater. 2020, 10, $1-14$.

31. Vimalanathan, P.; Venkateshwaran, N.; Srinivasan, S.P.; Santhanam, V.; Rajesh, M. Impact of surface adaptation and Acacia nilotica biofiller on static and dynamic properties of sisal fiber composite. Int. J. Polym. Anal. Charact. 2018, 23, 99-112.

32. Gumel, S.M.; Tijjani, A.A. Effect of chemical modifications on the mechanical properties of piliostigma thonningii fibre reinforced epoxy composites. Chem + Environ. Sci. 2017, 1, 1-15.

33. Azadi, M.; Sayar, H.; Ghalebahman, A.G.; Jafari, S.M. Tensile loading rate effect on mechanical properties and failure mechanisms in open-hole carbon fiber reinforced polymer composites by acoustic emission approach. Compos. Part B Eng. 2019, 158, 448-458. 